\title{
Academic staff and public communication: A survey of popular science publishing across 13 countries
}

\author{
Peter Bentley and Svein Kyvik
}

\begin{abstract}
This study is a cross-national empirical analysis of popular science publishing among university staff in a thirteen-country sample. The countries included in the study are: Argentina, Australia, Brazil, Canada, Finland, Germany, Hong Kong, Italy, Malaysia, Mexico, Norway, the United Kingdom, and the United States. The study seeks to quantify the extent of popular science publishing and its relationship with scientific publishing. Popular science publishing was measured as the number of articles written by scientists in newspapers and magazines over a three-year period 2005-2007. Our findings suggest that popular science publishing is undertaken by a minority of academic staff and to a far lesser extent than scientific publishing. Despite the arguably fewer rewards associated with publishing for the non-specialist public, our data suggests that academic staff with popular publications have higher levels of scientific publishing and academic rank. The positive relationship between scientific and popular publishing is consistent across all countries and academic fields. The extent of popular science publishing varies with field and country.
\end{abstract}

\section{Introduction}

In many countries, greater emphasis is now being placed on the dissemination of research results to a general or non-specialist public (Kalleberg 2000, Kyvik 2005, Scott 2005, Royal Society 2006a, Jensen et al. 2008, Peters et al. 2008b). Such activity, performed by science journalists or by academic staff themselves, is often labelled popularisation of research. The literature on science communication has dealt primarily with the role of science journalists in the popularisation of research, the relationship between researchers and journalists, and the way the general public receives and understands science news (Logan 2001, Weigold 2001). The focus of this article, however, will be on popularisation by academic staff members themselves.

Popularisation by academics can take different forms, such as articles in magazines and newspapers, public lectures, interviews with the press, and participation in radio and TV programmes. Such forms of popularisation have received little attention in the field of science studies (Felt 2003), and only a handful of single-country studies have attempted to quantify the extent of these activities in the academic community (Kyvik 1994, 2005, Jensen et al. 2008). Due to the accessibility of large databases that

\footnotetext{
${ }^{1}$ The final, definitive version of this paper has been published in Public Understanding of Science, vol. 20, issue 1, pp. 48-63, 2011, by SAGE Publications Ltd, All rights reserved. C [ http://pus.sagepub.com/content/20/1/48.abstract ]
} 
register scientific journal publishing and the comparable lack of data on popular science output, the fields of bibliometrics and scientometrics have focused entirely on the study of science publishing. We know of no multiple-country study that has examined the publishing of popular science articles for the non-specialist public.

The results of the few existing studies suggest that (a) popularisation of research is considered secondary to scientific publishing, (b) there are large individual differences in the propensity to perform such activities, (c) there is a positive relationship between scientific and popular publishing, and (d) popularisation of research is more common in the "soft sciences" (humanities, social sciences) than in the "hard sciences" (natural sciences, medicine, technology).

The purpose of this article is to examine these issues by using data on the number of articles published by university academics in newspapers and magazines across 13 countries: Argentina, Australia, Brazil, Canada, Finland, Germany, Hong Kong, Italy, Malaysia, Mexico, Norway, the United Kingdom, and the United States. Hong Kong is a semi-autonomous special administrative region of China, but for consistency in terminology it shall be referred to as a country. This data set enables us to examine the extent to which country specific results apply to a wider range of countries. Based on the former literature in this field, we will develop some propositions of what we can expect to find in this cross-national study.

(a) Popularisation of research is considered secondary to scientific publishing Several possible reasons have been given for why popular publishing remains secondary to scientific publishing. These include a lack of interest, time, rewards and incentives, and communication channels.

First, academic staff are often accused of being reluctant to engage themselves in communicating with the public because they are first and foremost interested in pursuing their research interests and in furthering their research career (Checkoway 2001). Thus, Gascoigne and Metcalfe (1997) found that Australian scientists regard public communication as an optional activity, not a basic part of their work. This viewpoint has, however, been questioned (Lewenstein 1995, The Royal Society 2006b).

Second, time pressure is a frequently used justification for not engaging with the public. Academics have a range of competing commitments and they will prioritise time on activities they perceive as more valuable to their career (Gascoigne and Metcalfe 1997). When asked how important it was to find time for public engagement compared to other work activities, the majority of British scientists saw public engagement as less important than other activities (Royal Society 2006b). Poliakoff and Webb (2007: 258) found that a perceived lack of time was associated with 
negative perceptions of popularisation, but did not predict actual participation. They conclude that perceived time pressures may affect perceptions of public engagement and mask broader concerns with the activity.

Third, although Dunwoody (1986) has argued that engagement with the public can be rewarding for many scientists in terms of personal satisfaction, public recognition, employer recognition, political recognition, and peer recognition, these factors are insufficient to motivate most academics to popularise their research. Several studies report that academic staff do not engage in popularisation because such activities are not rewarded financially, socially or in applications for promotion. Peters et al. (2008a) found that only a minority of epidemiology and stem cell researchers in France, Germany, Japan, UK and USA believed their media engagements had a mostly positive influence on their professional career. Enhanced public or professional reputation was rarely reported as motivations for media engagement. Among French scientists, Jensen et al. (2008) found that public dissemination had only a weak and generally insignificant effect on promotion. Overall, in comparison to other perceived drawbacks of popularisation (e.g. time constraints), negative peer attitudes is relatively minor concern (Royal Society 2006b, Wellcome Trust 2000, Poliakoff and Webb 2007). However, for the minority of staff who consider peer attitudes as important, this may be an important reason for not engaging in popularisation.

Fourth, a final argument is that even though academic staff might be interested in publishing articles for a lay public, they may have severe difficulties in finding a proper magazine or a newspaper that is willing to publish their story. While there are an abundance of scientific journals, there is a general shortage of popular science magazines that offer space for articles written by researchers themselves. In many cases, journalists would prefer to interview scientists and scholars and make their own story. Moreover, Jensen et al. (2008) argue that media engagements are driven by an external demand and invitations are generally received by a small group of highly visible scientists.

(b) There are large individual differences in the propensity to popularise research Given that public dissemination is considered by many as a secondary or optional activity, it is unsurprising that academics differ to a greater extent in their popular publishing than scientific publishing. In two previous Norwegian surveys, half of all popular science articles were published by 6 percent of all tenured university staff, while half of all scientific articles were published by roughly 20 percent of the staff (Kyvik 1994; 2005). Whereas scientific publishing was stable across age groups, academics over 40 years of age published twice as many popular articles compared to those under 40. The Wellcome Trust (2000) survey of British scientists found that only 13 percent had published a popular science or newspaper article in the previous 
year, and only 26 percent at least once during their career. The Royal Society's (2006b) survey, which included a broader definition of publishing for the nonspecialist public (including for the media, articles and books), found that 25 percent of scientists had written popular articles in the previous 12 months. The Royal Society (2006b) also found broader forms of public engagement were more likely to be undertaken by senior ranking academics. These patterns were also supported by Jensen et al. (2008), where 86 percent of senior ranking French scientists were involved in public engagement activities, compared to 14 percent of junior staff.

\section{(c) There is a positive relationship between scientific and popular publishing}

Former studies indicate that writing for the non-specialist public is related to a commitment to scientific publishing. Consistent across academic fields, Norwegian academics with popular articles published around 40 percent more scientific publications than those without popular publications (Kyvik 1994, 2005). More broadly, Jensen et al. (2008) concluded that popularisation is an activity of the French scientific "elite", with those involved with press, radio, and public conferences having significantly higher than average scientific bibliometric indices. Peters et al. (2008a) also found frequency of media contact increased with higher levels of peer reviewed publications among epidemiology and stem cell researchers.

(d) Popularisation of research is more common in the "soft sciences" than in the "hard sciences"

A common argument is that it is not possible or meaningful to popularise research in highly codified disciplines, such as mathematics or chemistry. Surveys of Norwegian academics have consistently found popular science publishing to be more extensive in the humanities and social sciences, compared to the natural sciences and technology (Kyvik 1994, 2005). One of the barriers to publishing for the lay public is the belief by scientists in a public deficit in either literacy or interest in science (Winter 2004). The perception of public ignorance or disinterest in scientific research may be greater in highly codified fields where disciplinary terminology must be translated into plain language for public communication. Dunwoody (1986) argues that newspaper editors perceive social science research as more relevant to the lay public audience, leaving less space for other fields of research. Scientists within some scientific disciplines, such as physics and geology, perceive their research as uncontroversial, rarely engage in disputes outside their discipline, lack training in communicating disciplinary knowledge in plain language and believe in a public deficit in science literacy (Winter 2004). The belief in a public ignorance or disinterest in science may therefore shape the perceived and actual opportunities for popular publishing in some disciplines.

(e) There are national differences in the extent of popular science publishing No previous multi-country studies have examined popular science publishing and little is known on how differences across countries may affect engagement in public 
communication. However, there are several reasons why the extent of popular publishing might differ. First, some countries, more than others, have long traditions of dissemination of scientific knowledge to the lay public; in Europe dating back to the age of the enlightenment, and in the United States to the early nineteenth century (Gregory and Miller 1998). Second, norms for proper engagement with the public may vary. Third, the level of "civic scientific literacy" and "public understanding of science” probably differs greatly across countries. A study by Miller (1998) indicates that a larger proportion of the population in the USA than in the European Union can be classified as scientific literate, and that in the latter group of countries the UK ranks first. Many African, Asian and Latin-American countries would probably earn a low score on a similar index. Public dissemination will be affected by the extent to which there is an educated population interested in reading about advances in science and technology, as well as interpretations of social and cultural phenomena. Fourth, there might be national differences in the quantity of popular science magazines and newspapers, their willingness to publish contributions by academics, or in the degree to which science journalism is developed as a profession. If science journalists disseminate research findings on behalf of academics, the role of academics may be limited. Finally, there might be national differences pertaining to the need by academic staff to "go public". In the competition for research funding, media visibility may be an important strategy to gain political recognition and support (Weingart 1998, Peters et al. 2008a).

\section{Data and methods}

The data for this article comes from the Changing Nature of the Academic Profession (CAP) project, an international survey of academics conducted in 2007/2008 (University of Kassel 2008). The main target population of the CAP project were academic staff in higher education institutions offering a baccalaureate degree or higher. To improve cross-national comparability, the CAP project used a common survey instrument and random sampling protocol. In this article we restrict ourselves to a subset of the CAP sample: full-time academic staff (with 30 hours or more per week) at research universities. We also restrict ourselves to 13 of the 17 countries where data is currently available, due to insufficiently few respondents from research universities (Japan), low response rates (below 10 percent in Korea and Portugal) or high non-response to the dependent variable (36 percent in China).

The common sampling protocol ensured some degree of consistency across selected countries. The response rates, including partially completed responses, were mostly below 40 percent (see Table 1). While the national samples were found to be broadly representative of the respective populations on strata such as gender, academic rank 
and institutional type, non-respondents may differ from respondents in their research profile. Therefore, there is a risk of non-response bias in the sample.

The CAP questionnaire required respondents to specify their number of scholarly contributions over the previous three years. Non-response was a particular problem for this question. Some respondents, identified as research staff, either skipped the entire research section of the survey or left the relevant question on research publications unanswered. It is very difficult to interpret these missing responses. A lack of answer may indicate that the question was not applicable or that they did not know or wish to reveal their research output. However, one could speculate that some respondents without any publications chose to leave the question unanswered rather than entering a zero into every appropriate box. We decided to remove all nonrespondents from the sub-sample, rather than recoding their answers to zero publications. This will likely underestimate the proportion of non-publishers, particularly in Malaysia where 11 percent of university staff did not answer the research question. The response rates and proportion of staff excluded due to nonresponse are listed in Table 1.

Table 1 Number of survey invitations; number of surveys returned; response rate; percentage of full-time university staff who did not answer the research question; number of remaining full-time academic staff $(N)$

\begin{tabular}{lccccc}
\hline & $\begin{array}{c}\text { Surveys } \\
\text { sent }\end{array}$ & $\begin{array}{c}\text { Surveys } \\
\text { returned }\end{array}$ & $\begin{array}{c}\text { Response } \\
\text { rate }\end{array}$ & $\begin{array}{c}\text { No research } \\
\text { answer }\end{array}$ & $(N)$ \\
\hline Argentina & 3,438 & 826 & $24 \%$ & $0 \%$ & $(378)$ \\
Australia & 5,496 & 1,381 & $25 \%$ & $3 \%$ & $(660)$ \\
Brazil* & 4,702 & 1,200 & $26 \%$ & $0 \%$ & $(368)$ \\
Canada & 6,693 & 1,152 & $17 \%$ & $5 \%$ & $(897)$ \\
Finland & 3,902 & 1,115 & $29 \%$ & $4 \%$ & $(629)$ \\
Germany* & 3,891 & 1,246 & $32 \%$ & $4 \%$ & $(661)$ \\
Hong Kong & 6,291 & 811 & $13 \%$ & $4 \%$ & $(596)$ \\
Italy & 4,797 & 1,701 & $35 \%$ & $2 \%$ & $(1,466)$ \\
Malaysia* & 3,401 & 1,113 & $33 \%$ & $11 \%$ & $(480)$ \\
Mexico & 986 & 680 & $69 \%$ & $1 \%$ & $(429)$ \\
Norway & 2,719 & 949 & $35 \%$ & $3 \%$ & $(535)$ \\
UK* & 11,000 & 1,663 & $15 \%$ & $3 \%$ & $(613)$ \\
USA & 3,732 & 848 & $23 \%$ & $4 \%$ & $(671)$ \\
\hline Total & 61,048 & 14,685 & $29 \%$ & $3 \%$ & $(8,383)$ \\
\hline
\end{tabular}

* Surveys sent, Surveys returned and Response rate includes a small number of non-university institutions

The CAP data included information on publishing activities of 8,383 full-time academic staff members during the three year period 2005-2007. Academic staff were re-classified according to the guidelines of the UNESCO (1978), from 11 disciplinary categories into five academic fields of learning: the social sciences (Education; Social and behavioural sciences; Business and economics; Law; Personal, transport and 
security services), humanities (Humanities and arts), natural sciences (Life sciences; Physical sciences, mathematics, computer sciences; Agriculture), technology (Engineering, manufacturing and construction, architecture) and medical sciences (Medical sciences, health related sciences, social services). Social sciences and natural sciences are the academic fields with the highest number of respondents, but the distribution across these categories differs across the 13 countries examined (see Table 2).

Table 2 Percent of full-time academic staff by field

\begin{tabular}{lcccccc}
\hline & Soc. Sci. & Hum. & Nat. Sci. & Tech. & Med. Sc. & Total \\
\hline Argentina & 19 & 13 & 36 & 21 & 10 & 100 \\
Australia & 34 & 14 & 23 & 7 & 22 & 100 \\
Brazil & 28 & 9 & 29 & 11 & 24 & 100 \\
Canada & 38 & 17 & 22 & 8 & 14 & 100 \\
Finland & 31 & 13 & 25 & 15 & 16 & 100 \\
Germany & 24 & 13 & 28 & 15 & 21 & 100 \\
Hong Kong & 44 & 19 & 13 & 10 & 14 & 100 \\
Italy & 21 & 12 & 40 & 16 & 11 & 100 \\
Malaysia & 22 & 8 & 23 & 34 & 12 & 100 \\
Mexico & 29 & 10 & 33 & 14 & 14 & 100 \\
Norway & 31 & 16 & 25 & 9 & 20 & 100 \\
UK & 34 & 21 & 19 & 10 & 16 & 100 \\
USA & 35 & 22 & 19 & 10 & 15 & 100 \\
\hline Total (mean) & 30 & 14 & 26 & 14 & 15 & 100 \\
\hline
\end{tabular}

The distribution of academic staff across fields in the different countries affects estimates of scientific and popular publishing. While significant variation exists within academic fields, journal articles are the traditional publication channel for scientific communication in the natural sciences, medicine and technology, while books are relatively more common in the humanities and social sciences (Creamer 1998). Regarding popularisation of research, higher publication rates have been reported in the humanities and social sciences (Kyvik 1994; 2005). Therefore, the distribution of academics by field in each national sample will likely affect international comparisons across publication types.

As Hilgartner (1990) has argued, popularisation is a matter of degree. The boundary between scientific research and popular versions of this research can be drawn at different points, and these ambiguities leave some flexibility concerning which articles should be regarded as scientific/scholarly versus popular. In this article, we examine several types of publications. Authored books, edited books and articles published in an academic journal or book, are considered scientific publications. Articles written by academics in newspapers and magazines are considered popular publications. However, some journal articles or books may have been published in 
non-peer reviewed channels, likely leading to an overlap between scientific and popular publishing.

Research indexes that give more weight to book publications over articles and fractionalise publications based on the number of authors, have been shown to markedly reduce disparities in average productivity across fields of learning (Kyvik and Teigen 1996). To recognise the relative contributions of each scientific publication type and offset differences across fields, scientific publications shall be expressed in terms of "article equivalents". In this study, article equivalents shall be calculated as a weighted sum of journal/book articles (1 point per article), books edited ( 2 points) and books authored (5 points) for each academic. Unfortunately the CAP data does not distinguish between solo and multi-authored publications. Therefore, publications with more than one author will be counted more than once, if both co-authors are included in the sample. This will likely overestimate scientific publication rates, particularly within the "hard sciences" where joint-authorship is more common (Creamer 1998).

We have applied tests of significance to check the robustness of differences in popular publishing. When making pairwise comparisons, such as between senior and junior ranked staff, we adopt an independent samples t-test with a 95 percent significance level. Multiple pairwise comparisons, such as between each of the 13 countries, are based on one-way ANOVA Games-Howell multiple comparisons with a 95 percent significance level. This choice is justified based on the unequal group sizes, variance and positively skewed (non-normal) distribution of the popular articles. The GamesHowell test is preferable under such sub-optimal conditions as it maintains robust significance levels (Jaccard et al. 1984).

Previous studies suggest popularisation is positively associated with the number of scientific publications, senior academic rank, location within the "soft" academic fields and a stronger commitment to public dissemination as an academic duty. Given the secondary nature of popular publishing, those engaging in popularisation probably also report more time on voluntary and unpaid activities beyond the core tasks of teaching, research and administration. Due to the skewness of popular publishing, we shall use binary logistic regression to identify how each of these factors independently affect the likelihood of academics publishing at least one popular article. The independent variables are operationalised in the following ways:

Female is a dichotomous variable (yes $=1$; no $=0$ ).

Senior rank is a dichotomous variable (senior academic rank=1; junior rank=0). 
Level of scientific publishing consists of three dichotomous variables: "low scientific publishing” (0 to 2 article equivalents; bottom quartile), “medium” (3 to 14; middle two quartiles) and "high scientific publishing” (15 or more; top quartile). Medium shall be the reference group.

Obligation to popularise research is a dichotomous variable based on agreement with the statement: "Faculty in my discipline have a professional obligation to apply their knowledge to problems in society” (strongly agree/agree=1; neutral/disagree=0).

Hours on core activities is a continuous variable based on self-reported hours spent by academics per week on "teaching”, “research” and "administration” during the teaching and non-teaching periods. We consider the teaching period as twice as long as the non-teaching period and weight the working time estimates accordingly, except in Mexico where the non-teaching period is not included due to lack of data.

Hours on non-core activities is based on self-reported hours spent on "service" (service to clients and/or patients, unpaid consulting, public or voluntary services) and "other academic activities" (activities other than teaching, research and administration).

Academic field consists of five dichotomous variables: "social sciences", "humanities”, “natural sciences”, "technology” and "medical sciences”. Humanities shall be the reference group.

Country consists of 13 dichotomous variables. Germany shall be the reference group.

\section{Results}

The number of academics publishing for the scientific community is far greater than those publishing for the non-specialist public. Over 90 percent of the academic staff included in the CAP survey had at least one scientific publication (article equivalent) during the 3 year period (2005-2007), but only a third published a popular article. Regarding scientific publishing, academic staff across the 13 countries published, on average, 0.6 authored books, 0.4 edited books and 7.2 articles in a book or journal. In contrast, the mean number of popular articles did not amount to more than 1.6 over the three-year period.

Popular publishing is extremely skewed; half of all popular articles were published by 3 percent of all academic staff, with the top 1 percent producing 31 percent of all popular articles. Overall, scientific publishing is considerably less skewed than popular articles, with half of all article equivalents published by 18 percent of all staff members. 
There are noticeable differences across academic fields in the proportion of academic staff publishing popular articles (Table 3). Academics in the natural sciences were significantly less likely to report a popular article compared to academics in all other fields except technology. Academics in the social sciences averaged significantly more popular articles than academics in the natural sciences and technology, but differences with other fields were insignificant. When comparing popular science publishing between fields within each of the 13 countries, the natural sciences tends to have the lowest levels of publishing, but many of the field differences are insignificant. The proportion of academic staff producing half of all popular articles varies only slightly across fields, from 3 percent in the social sciences and natural sciences to 4 percent in the other fields. This indicates that while popular publishing is more common within the social sciences, the higher mean is partly due to a small number of prolific publishers.

Table 3 Popular articles and article equivalents, 2005-2007, by field: mean, standard deviation, percent of academic staff with at least one publication and ratio of article equivalents to popular articles

\begin{tabular}{lccccccc}
\hline & & Soc. Sci. & Hum. & Nat. Sci. & Tech. & Med. & Total \\
\hline Popular & Mean & 2.1 & 1.5 & 1.3 & 1.2 & 1.7 & 1.6 \\
articles & Std dev. & 8.0 & 4.5 & 4.8 & 3.4 & 5.7 & 5.9 \\
& $\%$ & 38 & 33 & 27 & 31 & 35 & 34 \\
Article & Mean & 10.2 & 11.3 & 11.2 & 9.3 & 13.2 & 11.0 \\
equivalents & Std dev. & 10.3 & 11.7 & 12.3 & 12.4 & 15.5 & 12.3 \\
& $\%$ & 92 & 93 & 93 & 86 & 92 & 91 \\
Ratio & & 4.9 & 7.5 & 8.6 & 7.8 & 7.8 & 6.9 \\
\hline
\end{tabular}

There are also differences in scientific publishing across academic fields (Table 3). The inclusion of books and the use of a weighted index for article equivalents helped minimise differences across fields, as book publications were more common among academic staff in the social sciences and humanities, while journal/book articles were more common in the natural sciences. The higher rates of scientific publication in the medical and natural sciences is consistent with previous studies (Creamer 1998) and may partly be due to the stronger tradition of co-authorship and associated lack of fractionalisation based on the number of authors in the CAP data. Academics publish around eight article equivalents per popular article in all fields except the social sciences where the ratio is approximately closer to five. These field differences are as expected, but given the skewed nature of publishing in general and popular publishing in particular, these findings should be treated with caution.

On average, academics in Hong Kong reported the greatest number of popular articles in newspapers and magazines (2.3), followed by Germany (2.0), Norway (2.0) and Argentina (1.9). Popular publishing in each of these countries, plus Finland (1.5) and 
Canada (1.4), differed significantly from the two countries with the least popular articles, Malaysia (0.7) and the United Kingdom (0.7). Participation in popular publishing ranged from almost half of all academic staff in Argentina, to under one fifth in Malaysia. Academics were significantly more likely to have popular publications in Argentina, Canada, Finland and Norway, compared to the USA, UK, Italy and Malaysia.

Weighted as article equivalents, mean scientific publishing was greatest in Germany (14.7) and Italy (14.6), significantly more than all other countries except Hong Kong. Academics in most countries averaged between five to six article equivalents per popular article, but the ratio is highest in the UK (13.6) and Malaysia (12.1). The higher levels of popular science publishing in Hong Kong and greater ratio of article equivalents to popular articles in Malaysia, may be related to field differences. In Hong Kong, a relatively high proportion of staff are in the social sciences, where popular publishing tends to be stronger (see Table 2). In Malaysia, a high proportion of staff are in technology, a field with typically lower levels of popular publishing. However, the low levels of popular publishing in the English speaking countries appear despite a relatively high proportion of staff in the social sciences and humanities. Further, in English speaking countries, academics in technology are more likely to publish popular articles than social scientists or humanists.

Table 4 Popular articles and article equivalents, 2005-2007, by country: mean, standard deviation, percent of academic staff with at least one publication and ratio of article equivalents to popular articles

\begin{tabular}{|c|c|c|c|c|c|c|c|c|}
\hline \multirow[b]{2}{*}{ Country } & \multicolumn{3}{|c|}{ Popular articles } & \multicolumn{3}{|c|}{ Article equivalents } & \multirow[t]{2}{*}{ Ratio } & \multirow[t]{2}{*}{$(\mathrm{N})$} \\
\hline & Mean & $\begin{array}{c}\text { St. } \\
\text { Dev }\end{array}$ & $\%$ & Mean & St. dev & $\%$ & & \\
\hline Argentina & 1.9 & 4.2 & 49 & 10.4 & 13.4 & 89 & 5.5 & (378) \\
\hline Australia & 1.4 & 5.8 & 31 & 9.2 & 10.2 & 92 & 6.6 & $(660)$ \\
\hline Brazil & 1.7 & 6.1 & 37 & 10.0 & 11.3 & 92 & 5.9 & (368) \\
\hline Canada & 1.4 & 3.0 & 42 & 8.7 & 8.5 & 92 & 6.2 & (897) \\
\hline Finland & 1.5 & 3.7 & 41 & 10.1 & 12.4 & 89 & 6.7 & (629) \\
\hline Germany & 2.0 & 6.4 & 35 & 14.7 & 15.1 & 95 & 7.4 & (661) \\
\hline Hong $\mathrm{K}$. & 2.3 & 8.7 & 34 & 13.1 & 15.2 & 94 & 5.7 & (596) \\
\hline Italy & 1.8 & 7.3 & 28 & 14.6 & 13.5 & 97 & 8.1 & $(1,466)$ \\
\hline Malaysia & 0.7 & 2.7 & 20 & 8.5 & 11.4 & 81 & 12.1 & $(480)$ \\
\hline Mexico & 1.7 & 7.7 & 37 & 7.8 & 8.4 & 82 & 4.6 & (429) \\
\hline Norway & 2.0 & 7.6 & 40 & 11.7 & 12.5 & 92 & 5.9 & (535) \\
\hline UK & 0.7 & 2.0 & 26 & 9.5 & 9.8 & 93 & 13.6 & (613) \\
\hline USA & 1.2 & 4.9 & 30 & 6.9 & 8.6 & 82 & 5.8 & (671) \\
\hline Total & 1.6 & 5.4 & 35 & 10.4 & 11.6 & 90 & 6.5 & $(8,383)$ \\
\hline
\end{tabular}

The contention by some scientists that popularisation is an activity conducted by those not good enough for an academic career (Royal Society 2006b) does not receive much 
support in our data. Academics participating in popular publishing averaged significantly more article equivalents (13.5) than those without any popular articles (9.5). The difference between these groups is significant within all countries except the United States, where it is positive but statistically insignificant. The positive association between popularisation and scientific publishing is consistent with previous studies (Kyvik 2005; Jensen et al. 2008; Peters et al. 2008). When academics are categorised into quartiles based on their number article equivalents relative to others within their country, those in the top quartile average significantly more popular articles (2.7) than other academics (1.2). These high scientific publishers are also significantly more likely to report at least one popular article (46 percent) compared to other academics (30 percent). Academics with high levels of article equivalents average more popular articles than other academics in each of the 13 countries and the differences are significant in all countries except USA, Mexico, Hong Kong, Brazil and Australia.

Compared to academics in junior ranks, senior ranking academics published, on average, significantly more article equivalents (13.2 versus 7.7$)$ and popular articles (1.9 versus 1.1 ). Lower ranked academics were also significantly less likely to have published a popular article (28 versus 38 percent). However, while this may indicate that some junior ranked staff hold concerns about how popularisation is viewed by their superiors, 10 percent of junior staff are without publications of any type compared to 4 percent of senior academics. Academics aged 40 years or younger are significantly less likely to publish a popular article compared to older academics (28 versus 36 percent) and publish significantly fewer such articles (1.2 versus 1.8). However, differences in mean popular publications based on age are significant only in Finland, Germany, Hong Kong, Malaysia and USA. This is somewhat inconsistent with previous studies of popular publishing (Kyvik 2005, Jensen et al. 2008) and popularisation more generally (Royal Society 2006b) which found younger staff to be less likely to engage in such activities. Male academics, on average, published significantly more popular articles than females (1.8 versus 1.2$)$ and were significantly more likely to have published at least one such article (35 versus 32 percent). However, differences are rarely significant within individual countries and partly reflect gender differences in scientific publishing and rank.

Full-time academics in the CAP data averaged 48.3 hours per week. Academics with popular publications worked significantly more hours per week compared to those without popular articles (49.3 versus 47.8 hours), including significantly more hours on unpaid service to clients and other activities (8.3 versus 6.2 hours). However, academics with popular publications reported significantly fewer hours on the core tasks of teaching, research and administration (39.0 versus 40.1 hours). Differences in hours spent on non-core tasks are significant in each of the 13 countries. This indicates that those with popular articles may have slightly more discretionary hours to dedicate to voluntary or secondary activities. However, it is also likely that working 
time patterns reflect the perceived value of public engagement relative to the core activities (Poliakoff and Webb 2007).

The binary logistic regression model (Table 5) shows the effect of each independent variable on the probability of publishing at least one popular article. Academics in the humanities and Germany, with medium scientific publishing (3 to 14 article equivalents), operate as the reference groups due to their moderate levels of popular publishing participation. The effects of each of the behavioural factors (variables other than field or country) are broadly consistent within each of the 13 countries. Being among the top quartile of all scientific publishers is the strongest dichotomous factor positively associated with participation in popular publishing. This lends support to the hypothesis that academics with strong scientific publication records have more opportunities to popularise their research. Academics in the bottom quartile of scientific publishers are significantly less likely to publish popular articles, but the negative effect of this factor is relatively small. Somewhat surprisingly, being female is negatively associated with popular publishing, even after controlling for the positive effects of senior rank. Those who believed that academics have a professional obligation to apply their knowledge to problems in society are more likely to publish popular articles. Each additional hour dedicated to service and other non-core activities also increased the likelihood of popular publications, but hours spent on the core academic duties (teaching, research and administration) had no effect. 
Table 5 Binary logistic regression for factors affecting the odds of having at least one popular publication

\begin{tabular}{lccc}
\hline Predictor & B & S.E. & Exp (B) \\
\hline Constant & $-1.27^{* *}$ & 0.16 & 0.28 \\
\hline High scientific publishing & $0.54^{* *}$ & 0.06 & 1.71 \\
Obligation to popularise & $0.39^{* *}$ & 0.06 & 1.48 \\
Senior rank & $0.23^{* *}$ & 0.06 & 1.25 \\
Non-core activities (hours) & $0.03^{* *}$ & 0.00 & 1.03 \\
Core activities (hours) & 0.00 & 0.00 & 1.00 \\
Female & $-0.18^{* *}$ & 0.06 & 0.84 \\
Low scientific publishing & $-0.19^{*}$ & 0.07 & 0.83 \\
\hline Social sciences & 0.09 & 0.07 & 1.09 \\
Technology & -0.18 & 0.10 & 0.84 \\
Medical sciences & $-0.31^{* *}$ & 0.09 & 0.74 \\
Natural sciences & $-0.36^{* *}$ & 0.08 & 0.70 \\
\hline Argentina & $1.00^{* *}$ & 0.14 & 2.71 \\
Finland & $0.61^{* *}$ & 0.14 & 1.84 \\
Canada & $0.44^{* *}$ & 0.12 & 1.55 \\
Norway & $0.36^{*}$ & 0.15 & 1.44 \\
Brazil & 0.27 & 0.17 & 1.31 \\
Mexico & 0.18 & 0.15 & 1.20 \\
Australia & 0.03 & 0.14 & 1.03 \\
Hong Kong & 0.00 & 0.13 & 1.00 \\
USA & -0.08 & 0.13 & 0.92 \\
Italy & -0.20 & 0.11 & 0.82 \\
UK & -0.27 & 0.14 & 0.76 \\
Malaysia & $-0.51^{* *}$ & 0.18 & 0.60 \\
\hline Referace categories: & 0.90 \\
\hline
\end{tabular}

Reference categories: Medium scientific publishing (3 to 14 article equivalents), Humanities and Germany.

Model Summary: -2 Log likelihood $=8331.55$; Nagelkerke R Square $=0.10$;

Significance level: ${ }^{* *} \mathrm{p}<0.01 * \mathrm{p}<0.05$

The results for the country and academic field variables are more difficult to interpret. While the overall negative effect of being located in the natural sciences is consistent with the bi-variate comparisons, the negative effect of medical sciences is mostly due to field differences in hours spent on non-core voluntary service activities, which are roughly twice as long in this field. If we run separate binary logistic regression models for each of the 13 countries, academic field is significant in eight countries. Natural sciences is negative in Canada, Hong Kong, Italy, Norway and UK, while technology is negative in Argentina, Finland, Hong Kong and Italy. However, the overall insignificance of technology within the combined sample masks the significant positive effect of this variable in Australia and the UK. Many of the differences in popular publishing across countries remain significant after controlling for the included behavioural and field variables, such as the strongly positive effect of 
location in Argentina, leaving a large amount of cross-country variance unexplained by the model.

\section{Discussion}

The results of this study raise at least six essential questions:

- To what extent are the survey results representative for the total population of academic staff in universities in each country?

- To what degree does our indicator on popular publishing resemble the view held by academics themselves on what constitutes this type of activity?

- How can the relatively low levels of popular publishing be explained?

- Why do we find such large individual differences in popular publishing?

- Why are popular articles by academic staff less common in the "hard" sciences than in the "soft" fields?

- Why do we find differences in popular publishing between individual countries?

\section{Reliability of data}

Regarding the reliability of our data, we know of only one study that has investigated the relationship between science publishing and publishing for a lay public using comparable data to the present study. In Norway, a mail survey undertaken in 2001 among university staff of the rank of assistant professor or higher, asked academics to provide information on the number of self-reported scientific and scholarly publications, as well as popular science articles, in the three-year period from 1998 to 2000 (Kyvik 2005). Their scientific and scholarly publications included four categories: (1) articles in scientific and scholarly journals; (2) articles in research books, text books, and conference proceedings; (3) research books and text books; and (4) reports that formed part of a publication series. The staff were also asked to specify the number of articles they had published in the same period that they would characterise as popular science.

Thus, the Norwegian study helps us to answer our first two questions. The response rate in the 2001 survey was 60 percent; in the Norwegian CAP-survey 35 percent. Both surveys cover a three-year period, with results based on self-reported number of scientific and popular publications. However, while the Norwegian study asked academic staff to report the number of popular science articles, the CAP survey asked staff to report only the number of popular articles written for a newspaper or magazine. A comparison of the results of these two surveys displays relatively similar results. During the years 1998-2000, the academic staff in Norwegian universities published on average 2.1 popular science articles and 9.0 scientific publications, while in the CAP-survey the equivalent numbers were 2.0 and 8.2. During the years 19982000, 50 percent of the academic staff reported to have published at least one popular 
science article; in the CAP-survey 40 percent had done so. This higher percentage in the former study may be due to a broader definition of popular publishing, thus encompassing other types of outlets than magazines and newspapers.

\section{Low levels of popular publishing and large individual differences}

Overall, the CAP results confirm the belief that popular publishing is far less common than scientific publishing and is still an activity committed to by a minority of scientists in most fields (Jensen et al. 2008, Royal Society 2006b). How can the relatively low levels of popular science publishing be explained and why do we find such large individual differences in popular science publishing? Previous studies have given several possible explanations for the overall lack of engagement in popularisation and why some academics find these activities problematic. These include a lack of interest, time, rewards or incentives, publishing outlets and experience in dissemination of research to the public.

Lack of interest: The low levels of participation in popular publishing compared to scientific publishing in the CAP data may indicate a relative lack of interest in popularisation, but it is difficult to conclude that this stems from an over-commitment to publishing for the scientific community. Academics with the highest levels of scientific publishing were most likely to publish popular articles and generally averaged more popular articles than other groups. This indicates that interest in publishing for the wider community may actually be complemented by a stronger commitment to publishing for the disciplinary community.

Lack of time: Academics may have a genuine interest in spending more time on public engagement, but the existing demands of teaching, research and administration may leave little time for additional duties. If academics believe that public engagement is a secondary activity, then it is doubtful whether time spent on public engagement will increase without a commensurate decrease in time spent on other activities. The CAP data indicated that full-time academics work about 48 hours per week, including around 40 hours per week on the core activities of teaching, research and administration. Academics with popular articles spend significantly fewer hours on the core activities, but significantly more hours on service and other activities and significantly more hours overall. The differences in total hours and core activities are small (about one hour) and rarely significant within each national sample, but academics with popular articles spend significantly more hours on unpaid service and other activities (about two hours) in each of the 13 countries. These additional hours significantly increase the likelihood of participating in popular publishing across most countries. While the overall long working hours in academia supports the argument that academics generally face a lack of time, it can not explain why popularisers consistently found about two extra hours per week for service and other activities. 
Lack of rewards and incentives: Unfortunately, there is no way of knowing how the incentive system affects motivation to publish popular articles in the CAP data, as these issues were not covered in the survey. Further, without historical publication and promotional data, the effect of popular publishing on one's chance for promotion is also not directly clear. However, indirectly we can say that compared to academics without popular articles, those with popular articles are significantly more likely to be in senior academic ranks (64 versus 54 percent). This finding may indicate that academics engaged in popularisation receive slightly higher extrinsic rewards. However, determining causality between popular publishing and other variables is not possible. For example, academics of higher ranks may be approached more often to write popular articles, thus academic rank may be both a cause as well as a consequence of popularisation.

Lack of publishing outlets: We have no data or information that might have illuminated this proposition.

Lack of experience: Gascoigne and Metcalfe (1997) found that Australian academics lacking experience or training with media communication were more likely to hold negative opinions of popular science publications. Inexperienced staff were also more likely to evaluate popular science by scientific standards and be embarrassed by the thought of their peers reading simplified explanations of their work. Qualitative findings suggest junior ranking and younger staff are keen to first establish a reputation within the research community before engaging outside (Royal Society 2006b). While we have no information in the CAP data on experience in media communication or the views of academics on popular publishing, we do find that younger academics publish significantly fewer popular articles than academics over the age of 40. However, younger academics also publish significantly fewer scientific articles. The number of article equivalents per popular article is very similar for younger academics (6.9) compared to older academics (6.7). Therefore there is no support in the CAP data suggesting younger academics prefer scientific publishing more than older academics.

\section{Field differences}

In the CAP data we found that academics in the natural sciences and technology published, on average, the fewest popular articles and were also least likely to have published any such articles. A possible reason is that academic staff in these fields do not have the public as an important and legitimate audience, simply because the general public is more interested in reading about cultural heritage, social problems and advances in medical treatment (Kyvik 2005). A related explanation is that academic staff in these fields may gain reputation in the general public, making them less dependent upon a particular set of specialist colleagues (Whitley 1984). Still another explanation is that natural scientists and technologists may have greater 
difficulties communicating their research in terms easily understood by the nonspecialist public (Kyvik 2005).

\section{National differences}

Why do we find such large differences in popular science publishing across the countries surveyed? This is a far more difficult proposition, given that this is the only known study to examine popularisation across multiple countries with comparable data and sampling techniques. In fact, we are not able to explain these differences, but will put forward some possible partial explanations. In the introduction, we suggested a number of possible reasons for national differences in the level of popular article publishing.

Firstly, there are long traditions of dissemination of scientific knowledge to the lay public in the United States and Europe (Gregory and Miller 1998). However, while popular publishing is generally more common in the continental European countries compared to Asian countries, popular publishing is comparably rare in the USA.

A second explanation may be national differences in the norms for proper publishing behaviour. In Norway, where popular science publishing is more common than in most other countries, dissemination of research to the public is included as one of the tasks of universities (though not by individual staff members) in addition to teaching and research (Kyvik 2005).

Third, differences in the level of "scientific literacy" across countries may affect the demand for popular science publications. However, there is little evidence to suggest a clear relationship. For example, Finland, Hong Kong and Canada are the top three ranking countries for average science literacy amongst high school students, while Mexico, Argentina and Brazil are amongst the lowest ranking countries (OECD 2006). While this may partly account for why academics in Hong Kong had the highest mean popular publications, it fails to explain why academics in Latin America are generally more engaged in popularisation than their counterparts in Englishspeaking countries where science literacy is apparently higher.

Given that academics are not the sole popularisers of science, a fourth explanation may lie in cultural differences pertaining to the role of media in science communication. In the UK, where scientists themselves are not very active, it has earlier been contended that the task of science reporting has increasingly fallen into the hands of journalists (Shortland and Gregory 1991). Thus, there might be less space in the media for scientists who want to publish popular science articles themselves.

Finally, there might be national differences in the need and incentives for academic staff to "go public" in order to compete for research funding, media visibility and 
political support (Weingart 1998, Peters et al. 2008a). Popular publishing may broaden one's channels for research funding and strengthens one's competitiveness within traditional channels. However, the comparably low level of popular publishing relative to scientific publishing in the UK, suggests that the perceived benefits of popularisation are not as important as additional scientific publications in highly competitive systems of research funding.

\section{References}

Checkoway, B. (2001) "Renewing the Civic Mission of the American Research University”, The Journal of Higher Education 72: 126-47.

Creamer, E. 1998, “Assessing Faculty Publication Productivity: Issues of Equity”, ASHE-ERIC Higher Education Report 26 (2), Washington D.C.

Dunwoody, S. (1986) "The Scientist as a Source”, in S.M. Friedman, S. Dunwoody and C.L. Rogers (eds) Scientists and Journalists: Reporting Science as News, pp. 316. New York: Free Press.

Felt, U. (2003) "Sciences, Science Studies and their Publics: Speculating on Future Relations”, in B. Joerges and H. Nowotny (eds) Social Studies of Science and Technology: Looking Back Ahead, pp. 11-31. Dordrecht: Kluwer Academic Publishers.

Gascoigne, T. and Metcalfe, J. (1997) "Incentives and Impediments to Scientists Communicating through the Media”, Science Communication 18 (3): 265-82.

Hilgartner, S. (1990) "The Dominant View of Popularisation: Conceptual Problems, Political Uses”, Social Studies of Science 20: 519-39.

Jaccard, J., Becker, M. A., \& Wood, G. (1984). "Pairwise multiple comparison procedures: A review”, Psychological Bulletin, 96: 589-596.

Jensen, P., Rouquier, J.B., Kreimer, P and Croissant, Y. (2008) "Scientists who engage with Society perform better academically”, Science and Public Policy 35 (7): 527-41.

Kalleberg, R. (2000) "Universities: Complex Bundle Institutions and the Projects of Enlightenment”, Comparative Social Research 19: 219-55.

Kyvik, S. (1994) “Popular Science Publishing”, Scientometrics 31 (2): 143-53.

Kyvik, S. (2005) "Popular Science Publishing and Contributions to Public Discourse among University Faculty”, Science Communication 26 (3): 288-311. 
Kyvik, S. and Teigen, M. (1996) "Child Care, Research Collaboration, and Gender Differences in Scientific Productivity”, Science, Technology and Human Values 21 (1): 54-7.

Lewenstein, B.V. (1995) "Science and the Media", in S, Jasanoff, G.E. Markle, J.C. Petersen and T. Pinch (eds) Handbook of Science and Technology Studies, pp. 343-60. Thousand Oaks: SAGE Publications.

Logan, R.A. (2001) “Science Mass Communication. Its Conceptual History”, Science Communication 23: 135-63.

Martín-Sempere, M. J., Garzón-García, B. \& Rey-Rocha, J. (2008) “Scientists' Motivation to Communicate Science and Technology to the Public: Surveying Participants at the Madrid Science Fair”, Public Understanding of Science, 17(3): 349-67.

Miller, J.D. (1998) “The Measurement of Civic Scientific Literacy”, Public Understanding of Science, 7 (3): 203-23.

OECD (2006) PISA 2006 Results, Paris: OECD.

Peters, H. P., Brossard, D., de Cheveigné, S., Dunwoody, S., Kallfass, M., Miller, S. (2008a) “Interactions with the Mass Media”, Science, 321: 204-5.

Peters, H. P., Brossard, D., de Cheveigné, S., Dunwoody, S., Kallfass, M., Miller, S. (2008b) “Science-Media Interface: It's Time to Reconsider”, Science Communication, 30: 266-76.

Poliakoff, E. and Webb,T.L. (2007) "What Factors Predict Scientists' Intentions to Participate in Public Engagement of Science Activities?”, Science Communication, 29 (2): 242-63.

Royal Society (2006a) Science and the Public Interest. Communicating the Results of new Scientific Research to the Public. London: The Royal Society.

Royal Society (2006b) Survey of Factors Affecting Science Communication by Scientists and Engineers. London: The Royal Society.

Scott, P. (2005) “The Academic Profession in a Knowledge Society”, in U. Teichler (ed) The Formative Years of Scholars, pp. 19-30. London: Portland Press.

Shortland, M. and Gregory, J. (1991) Communicating Science: A Handbook. Essex: Longman.

University of Kassel (2008) Changing Academic Profession. An International Research Project, Available: http://www.uni-kassel.de/wz1/cap/international.ghk

UNESCO (1978) Recommendation Concerning the International Standardization of Statistics on Science and Technology, Paris: UNESCO. 
Weingart, P. (1998) “Science and the media”, Research Policy, 27: 869-79.

Weigold, M.F. (2001) “Communicating Science: A Review of the Literature”, Science Communication 23: 164-93.

Wellcome Trust (2000) The Role of Scientists in Public Debate. Full Report. London: The Wellcome Trust.

Whitley, R. (1985) "Knowledge Producers and Knowledge acquirers: Popularisation as a Relation between Scientific Fields and their Publics”, in T. Shinn and R. Whitley (eds) Expository Science: Forms and Functions of Popularisation, pp. 3-28.

Dordrecht: Reidel.

Winter, E. (2004) "Public Communication of Science and Technology: German and European Perspectives”, Science Communication 25(3): 288-93. 


\section{University Library}

\section{- M M N E R VA A gateway to Melbourne's research publications}

Minerva Access is the Institutional Repository of The University of Melbourne

Author/s:

Bentley, P;Kyvik, S

Title:

Academic staff and public communication: a survey of popular science publishing across 13 countries

Date:

2011-01-01

Citation:

Bentley, P. \& Kyvik, S. (2011). Academic staff and public communication: a survey of popular science publishing across 13 countries. PUBLIC UNDERSTANDING OF SCIENCE, 20 (1), pp.48-63. https://doi.org/10.1177/0963662510384461.

Persistent Link:

http://hdl.handle.net/11343/113916 